\title{
Transient Expression of Acetylcholinesterase in the Posterior Ventral Cochlear Nucleus of Rat Brain
}

\author{
Barbara J. Morley, ${ }^{1}$ W. Bruce Warr, ${ }^{1}$ ANd Jorge Rodriguez-Sierra ${ }^{2}$ \\ ${ }^{1}$ Boys Town National Research Hospital, Omaha, NE 68131, USA \\ ${ }^{2}$ The Department of Cell Biology and Anatomy, University of Nebraska Medical Center, Omaha, NE 68198, USA
}

Received: 19 February 2004; Accepted: 1 June 2004; Online publication: 18 October 2004

\section{ABSTRACT}

In this report we partially characterize a pathway projecting to the posterior ventral cochlear nucleus $(\mathrm{PVCN})$ of the rat brain that transiently expresses a high level of acetylcholinesterase (AChE). The AChEpositive axons form a network that envelops a discrete region of the PVCN that includes the octopus cell region and some cells rostral to it. AChE is first detectable by postnatal day 3 (P3), peaks in expression at about $\mathrm{P} 7-10$, and is barely detectable in our preparations by $\mathrm{P} 15$. We previously reported that neurons in the octopus cell region express high levels of $\alpha 7$ nAChR mRNA and $\alpha$-bungarotoxin binding during the same time period. In light microscopic immunocytochemical studies using antibodies to the vesicular acetylcholine transporter (VAChT), we could not identify immunopositive boutons in the developing regions of the PVCN that express high levels of AChE-positive fibers despite distinct punctate labeling in other brain regions. Systematic electron microscopic examination of AChE histochemical staining throughout the PVCN revealed intense labeling of axons, but synaptic sites were devoid of reaction product. The source of the AChE-positive fibers is not known, but the fibers are not auditory nerve axons and probably not collaterals of the olivocochlear bundle.

Keywords: acetylcholinesterase, posterior ventral cochlear nucleus, octopus cell, rat, postnatal, development

Correspondence to: Barbara J. Morley - Boys Tow National Research Hosiptal 555 North 30th Street - Omaha, NE 68131. Telephone: (402) 498-6584; Fax: (402) 498-6351; email: morley@ boystown.org

\section{INTRODUCTION}

Acetylcholinesterase (AChE) is transiently expressed in several brain pathways during early postnatal development, with peak expression at about postnatal day 7 (P7) (Kristt 1983; Kristt and Waldman 1981; Robertson et al. 1991; Geula et al. 1993; Brimijoin and Hammond 1996; Bennett-Clarke et al. 1999). It is well known that AChE may be expressed by noncholinergic as well as cholinergic neurons (Eckenstein and Sofroniew 1983) and may have noncatalytic functions, particularly during development (Coleman and Taylor 1996; Koenigsberger et al. 1997; Bigbee et al. 2000). However, in regions where the AChE axons make contact with neurons that express an upregulation of the $\alpha 7$ nicotinic acetylcholine receptor (nAChR) at the same developmental age (Fuchs 1989; Bina et al. 1995; Broide et al. 1995; Levy and Aoki 2002), the AChE-positive pathways may be cholinergic. Electrophysiological evidence for functional $\alpha 7$ nAChRs associated with the transient postnatal AChE-positive thalamocortical tract was recently reported (Aramakis and Metherate 1998; Aramakis et al. 2000).

In this report we identify a similar pathway to the posterior ventral cochlear nucleus (PVCN) of the rat that forms a network of AChE-positive axons enveloping neurons in a region that includes the octopus cells. Peak expression is at about P7-10. Dynamic changes in the AChE-positive axons parallel an upregulation of $\alpha 7 \mathrm{nAChR}$ mRNA and $\alpha$-bungarotoxin binding in the octopus cell region during the same time period, as previously reported (Morley and Happe 2000). We tested the hypothesis that AChEpositive axons make cholinergic synaptic connections during this early postnatal period, using AChE light and EM histochemistry and vesicular acetylcholine 
transporter (VAChT) immunocytochemistry. The results suggest that synapses are present on somatic spines beginning by P3 and on both spines and somata by $\mathrm{P} 5$, but the AChE-positive axons apparently do not make contact at synaptic-like junctions.

To test the hypothesis that olivocochlear neurons might be a source of the transient AChE activity, we used the lipophilic carbocyanine fluorochrome dye, DiI, as an axonal tracer. DiI placed at the floor of the fourth ventricle resulted in robust labeling of the cells of origin of the olivocochlear bundle (OCB) in the superior olivary complex (SOC) and of axons entering the cochlear nucleus but not terminating in or passing through the PVCN.

The possible function of ACh and AChE in the maturation of glutamatergic synapses and the activation of neurons in the developing octopus cell region before the onset of hearing are discussed.

\section{MATERIALS AND METHODS}

\section{Animal care and use}

Care and animal use procedures were in strict accordance with the National Institutes of Health Guide for the Care and Use of Animals and were approved by the Boys Town National Research Hospital Animal Care and Use Committee.

\section{Acetylcholinesterase light histochemistry}

Rats at ages P3, P5-6, P7-8, P10, P12, P15, P18, P28 (3-6 animals per age) were perfused intracardially with $4 \%$ formaldehyde freshly prepared from depolymerized paraformaldehyde, $0.1 \mathrm{M}$ sodium phosphate, $\mathrm{pH} 7.4$, or $2 \%$ formaldehyde (prepared as described above), $2.5 \%$ glutaraldehyde, $0.1 \mathrm{M}$ sodium phosphate buffer, $\mathrm{pH}$ 7.4. Sections were cut at varying thickness from 10 to $50 \mu \mathrm{m}$ and in three planes of section (coronal, sagittal, horizontal) for the purpose of attempting to identify the orientation of the fibers entering the cochlear nucleus. Sections were cut on a cryostat and processed for AChE histochemistry using the silver intensification modification (Henderson 1967) of the Koelle and Friedenwald (1949) procedure. The reaction was carried out in the presence of $10^{-4} \mathrm{M}$ tetraisopropyl-pyrophosphoramide.

\section{Acetylcholinesterase EM histochemistry}

Rats at ages P3, P5-6, P7-8, P10, and P12 (2-3 animals per age) were perfused intracardially with $2 \%$ formaldehyde (prepared as described above) and $2.5 \%$ glutaraldehyde fixative in $0.1 \mathrm{M}$ sodium phosphate buffer $(\mathrm{pH} 7.4)$. Coronal $50-\mu \mathrm{m}$ sections were cut on a vibratome and processed for AChE histo- chemistry as described above. Additional sections were processed using the method of Karnovsky and Roots (1964). The sections used for this article were obtained from tissue stained with the Henderson procedure because the staining was more intense.

For one of the animals at each age that we processed for electron microscopy, all sections were reacted for AChE. Three representative $50-\mu \mathrm{m}$ sections (one each from the rostral, central, and caudal portion of the octopus cell region) were then chosen for thin sectioning and the localization of the reaction product determined. For a second animal, every other section was reacted for AChE. The sections were then cut in half at the midline and a digital image of each half-section containing the octopus cell region was captured. The half-sections were flat embedded in Araldite epoxy resin and the embedded slab was glued to a Beem capsule and oriented at a slight angle so that we would always be cutting into the leading edge (where the reaction product would be most intense). Semithin $(1-2 \mu \mathrm{m})$ sections were taken of the block face, lightly counterstained, and digitally overlaid onto the image of the original halfsection (see Fig. 6). Thin sections were then made using landmarks and the semithin section for orientation. Approximately 5-7 thin sections were made and collected, and 2-3 semithin sections were cut, followed by thin sections, etc., through to the $50-\mu \mathrm{m}$ section, such that we sampled areas from the entire section.

\section{AChE in situ hybridization}

Animals and tissue preparation. Rats at ages $\mathrm{P} 0, \mathrm{P} 6-7$, P10, and P90 (3 animals/age) were perfused with $4 \%$ formaldehyde (prepared as described above), $0.1 \mathrm{M}$ sodium phosphate, $\mathrm{pH} 6.5$, followed by $4 \%$ formaldehyde (prepared as described above), 0.1 M sodium phosphate, $0.05 \%$ glutaraldehyde, $\mathrm{pH} 9.5$, and postfixed in $4 \%$ formaldehyde (prepared as described above), $0.1 \mathrm{M}$ sodium phosphate, $\mathrm{pH} 9.5$, overnight and decalcified using Decalcifier $F$ (Baxter) for 7 days, rinsed in buffer, and cryopreserved in $27 \%$ buffered sucrose.

Riboprobes. A 402-bp segment of the rat AChE gene was amplified from rat brain using reverse transcriptase polymerase chain reaction (RT-PCR). RNA was isolated from rat brain and cDNA was amplified by RT-PCR using $20 \mathrm{pM}$ of the primer sequences GCTCACGTAGATTTATGCCACCAGA and

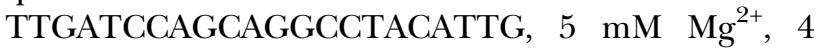
mM dNTP, $62 \mu \mathrm{l} \mathrm{Tag,} \mathrm{1.5} \mu \mathrm{l}$ RT-Mix (1:1) in a total of $25 \mu \mathrm{l}$ per sample. The cDNA was inserted into pGEM$\mathrm{T}$ Easy Vector (Promega) and linearized using NcoI (antisense) and PstI (sense). Antisense and sense probes were transcribed using ${ }^{35} \mathrm{~S}$-UTP with a specific 

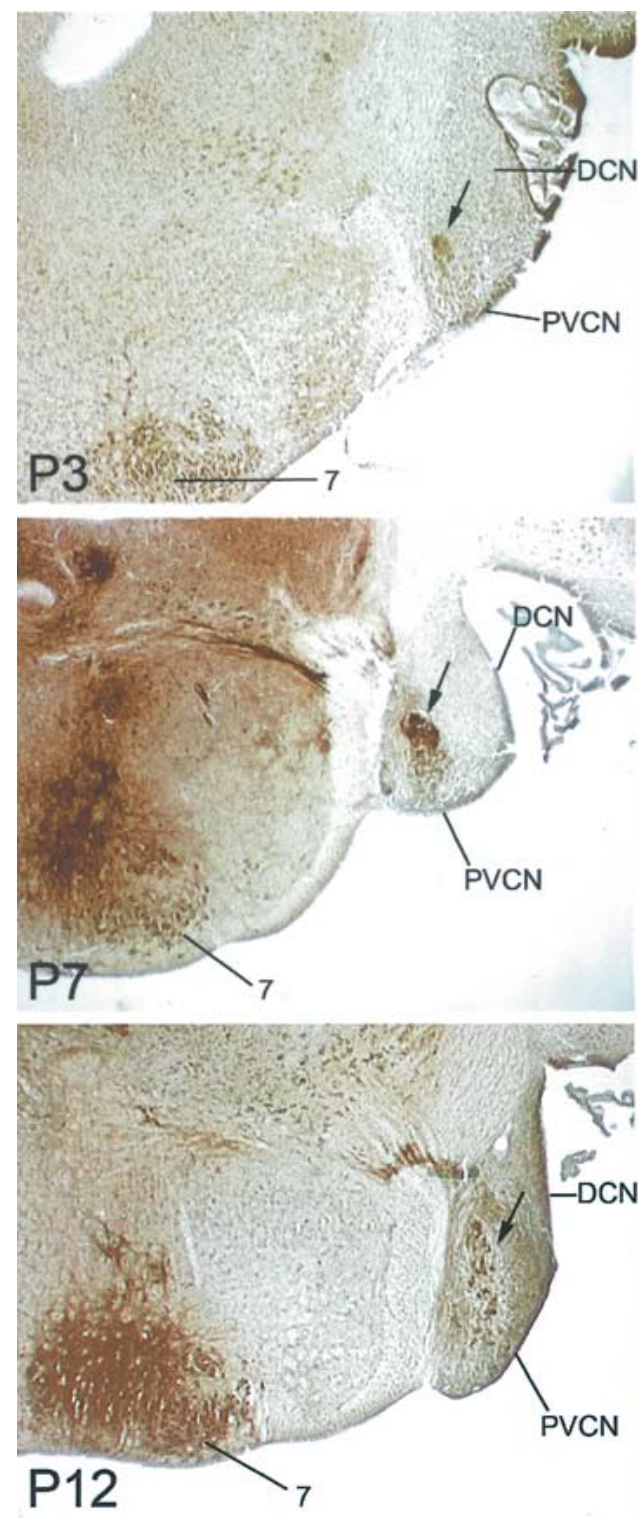
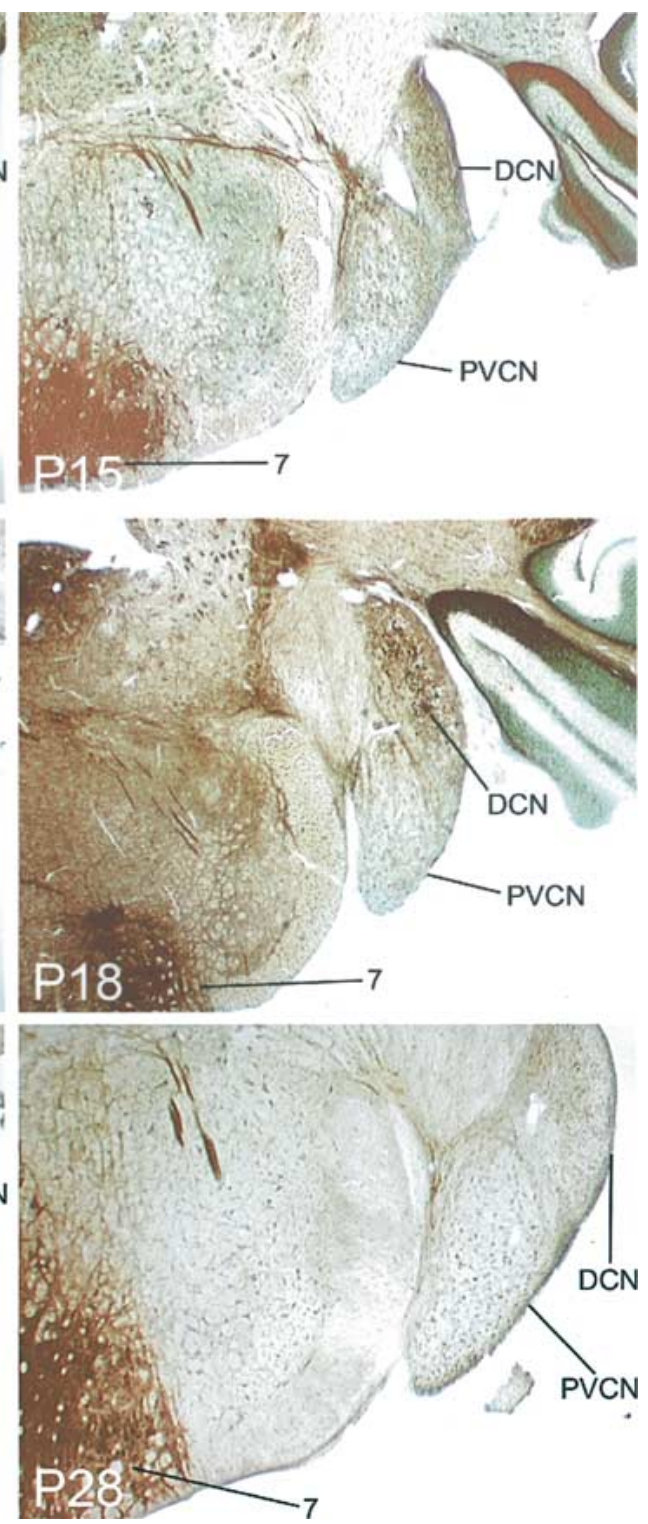

FIG. 1. AChE was visualized in $50-\mu \mathrm{m}$ cryostat sections of fixed rat brain using a silver intensification of the acetylcholinesterase histochemical stain. The sections were lightly counterstained with toluidine blue. Arrows indicate the AChE-positive areas in the developing octopus cell region. DCN, dorsal cochlear nucleus; PVCN, posterior ventral cochlear nucleus. activity of $1250 \mathrm{Ci} / \mathrm{mmol}$ (PerkinElmer Life Sciences/NEN) and the Ambion MAXIscript transcription Kit (Ambion, Inc.), as previously described) (Morley 1997).

In situ hybridization procedure. Sections were cut at $16 \mu \mathrm{m}$ on a Reichert 2800 E cryostat, freeze-thaw-mounted onto FisherFrost Plus glass slides, dried on a warming plate at $56^{\circ} \mathrm{C}$ for $1 \mathrm{~h}$, and stored desiccated for three days at $-70^{\circ} \mathrm{C}$. Slides were subsequently removed from the freezer, dried, and processed for in situ hybridization using standard techniques, as previously described (Morley 1997).

After completion of the in situ hybridization procedure, slides were air-dried and dipped in NT-3 emulsion (Kodak); developed 7 days later with D-19 diluted 1:1 with tap water (Kodak); fixed, dried, and exposed to RayMax Beta autoradiography film (ICN) for 10 days; and developed. Film images were cap- tured and analyzed for semiquantitative densitometry using MCID Elite, Version 6.0 (Imaging Research, Inc.). Standards containing known amounts of ${ }^{14} \mathrm{C}$ were exposed along with tissue on each film (Standard Series E146; Amersham).

\section{Vesicular acetylcholine transporter immunocytochemistry}

Rats at ages P0-3, P5, P7, P10, and P12 (4-6 animals/ age) were perfused intracardially with several fixatives, including 3\% formaldehyde (prepared as described above), $0.1 \mathrm{M}$ sodium phosphate, $\mathrm{pH} 7.4,4 \%$ formaldehyde (prepared as described above), $0.1 \mathrm{M}$ sodium phosphate, $\mathrm{pH} 7.4$, and the acid/base shift fixative described above for in situ hybridization. Tissues were postfixed for 4-24 h. Several fixatives and incubation times were used to eliminate the 
possibility that the absence of labeling was not due to poor fixation or overfixation.

Cryostat sections were cut at $10-50 \mu \mathrm{m}$ and processed either free-floating or after mounting on slides $(<30 \mu \mathrm{m}$ thickness). The primary antibody (goat antirat VAChT; ImmunoStar) was used in dilutions of 1/ 100 to $1 / 10,000$. The Vectastain Elite ABC-peroxidase kit (Vector) was used per the manufacturer's instructions or diluted to produce optimal labeling. The reaction product was visualized with diaminobenzidine (DAB) and enhanced with a DAB enhancing solution (Vector) or with the SG substrate kit for peroxidase (Vector). Optimal labeling was obtained with a $1 / 3000$ dilution of the primary antibody and a $1 / 200$ dilution of the Vector biotinylated second antibody for $1 \mathrm{~h}$ at room temperature and $2 \mathrm{~h}$ at $4^{\circ} \mathrm{C}$ and a $1 / 800$ dilution of the Vector biotin avidin complex overnight at $4^{\circ} \mathrm{C}$. Optimal suppression of background was obtained by preincubation of the tissue in buffered $20 \%$ fetal calf serum before incubation in the primary antibody, $0.3 \%$ Triton added to the primary antibody, and $2 \%$ rat serum and the appropriate blocking serum supplied with the Vector Elite Kit added to the secondary antibody. The tissue was washed for 5 min 5 times between steps. Sections were counterstained with toluidine blue (DAB substrate) or Nuclear Fast Red (SG substrate).

\section{Tracing procedures using Dil}

The lipophilic carbocyanine fluorochrome dye, DiI, has been demonstrated to be an effective axonal tracer in perinatal animals (Bruce et al. 2000). Two rat pups, $\mathrm{P} 8$ and $\mathrm{P} 10$, were deeply anesthetized with pentobarbital (IP) and perfused through the heart with $5 \mathrm{ml}$ phosphate-buffered saline $(0.1 \mathrm{M}, \mathrm{pH} 7.4)$ followed by $100 \mathrm{ml}$ phosphate-buffered fixative $(0.1$ $\mathrm{M}, \mathrm{pH}$ 7.4) containing $4 \%$ formaldehyde (prepared as described above), $0.25 \%$ glutaraldehyde, $4 \%$ dextrose, and $0.002 \%$ calcium chloride. After $24 \mathrm{~h}$ of immersion at $4^{\circ} \mathrm{C}$ in the same fixative, the brains were removed and the floor of the fourth ventricle exposed by removing the cerebellum. With the aid of an operation microscope, a 1-mm-deep cut was made between the facial genua in order to sever the decussating axons of the OCB, as well as those of the vestibular efferent bundle, using a No. 11 scalpel blade calibrated in 1-mm intervals from the tip. A piece of filter paper (approximately $2 \times 4 \mathrm{~mm}$ ) that had been previously soaked in a solution of DiI in dimethylformamide was inserted into the cut. The brains were then incubated in the dark at $37^{\circ} \mathrm{C}$ in fixative for 8 weeks.

Following incubation, the brains were rinsed in buffer and sectioned in the transverse plane at $50 \mu \mathrm{m}$

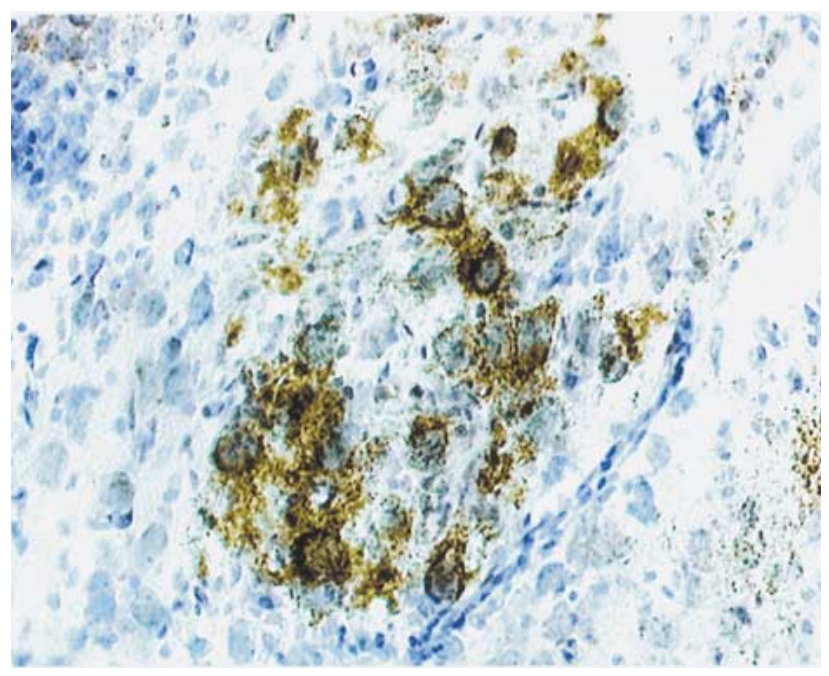

FIG. 2. A horizontal $30-\mu \mathrm{m}$ cryostat section through the octopus cell region of a P10 animal was histochemically labeled for AChE. The reaction product takes on the appearance of boutons because of the punctate nature of the stain. The section was counterstained with toluidine blue.

on a Vibratome. The sections were mounted on slides, coverslipped with Fluoromount, and viewed with a Zeiss Research epifluorescence microscope equipped with a 100-W mercury burner, a standard rhodamine filter set, and Neofluor objectives. In order to document the location of labeled axons and cell bodies, images were captured upon initial examination of the sections using a Hamamatsu black and white CCD video camera and controller, which was connected to a Sony Trinitron monitor and a PC running Image-Pro Plus software (Media Cybernetics).

\section{RESULTS}

\section{Acetylcholinesterase light microscopy istochemistry}

Tissue sections prepared for light microscopy demonstrated a clear transient expression of an AChEpositive projection into a region of the PVCN (Fig. 1). The reaction product can be observed in fibers entering the cochlear nucleus $(\mathrm{CN})$, The axons could not be traced far enough in serial sections to determine their origin. The distribution of reaction product is restricted to the PVCN and primarily, but not exclusively, surrounds the octopus cells (Fig. 2). The octopus cell region was identified using the description reported by Harrison and Irving (1966). Representative cross-sections through the PVCN of a P10 rat are shown in Figure 3. 

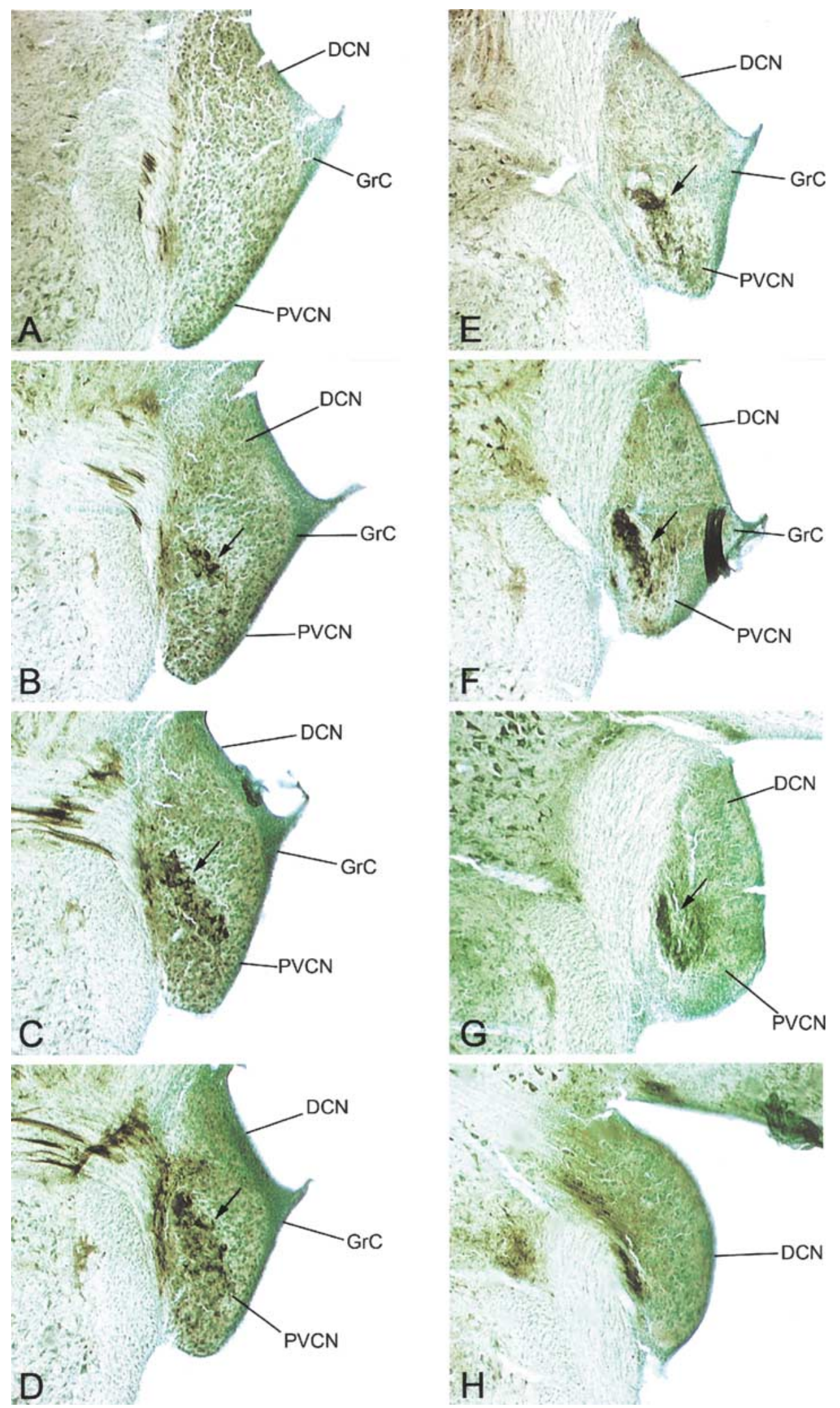

FIG. 3. Serial $50-\mu \mathrm{m}$ cryostat sections were cut through the cochlear nucleus of a P10 rat to visualize the spatial distribution of AChE. The intense labeling was restricted to the PVCN, most predominantly to the octopus cell region. The sections are counterstained with methyl green. The sections shown here are not all equally spaced through the $\mathrm{CN}$. The spacing, in microns, between

the sections is (A-B) 100; (B-C) 150; (C-D) 50; (D-E) 50; (E-F) 50; (F-G) 100; (G-H) 100. Arrows direct the reader to the AChE-positive regions in the octopus cell region. AVCN, anterior ventral cochlear nucleus; GrC, granule cell cap; PVCN posterior ventral cochlear nucleus. 

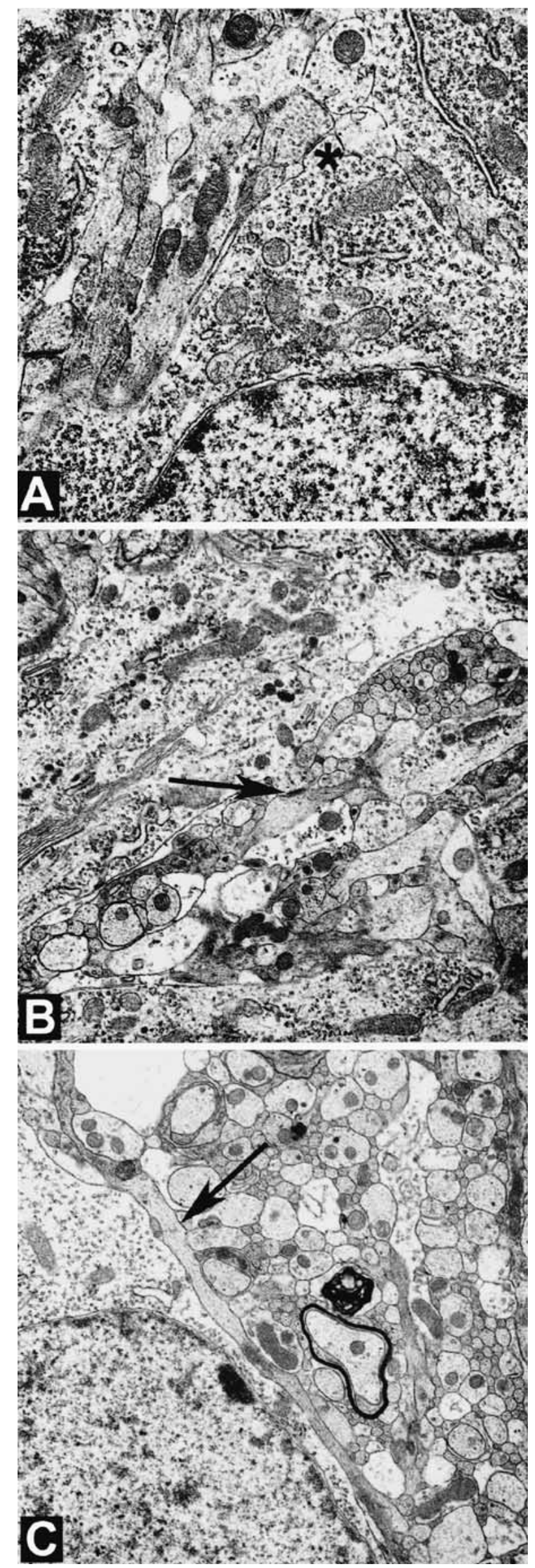

FIG. 4. Representative electron micrographs of the octopus cell region of a P3 rat. Synapses were rarely seen, but, when they did occur, they were localized on a blunt spine or an apparent axon of passage in the neuropil. No axosomatic synapses were observed at this age. A. A presynaptic bouton with large vesicles appears to contact a blunt spine $\left(^{*}\right)$. B. A second bouton synapses $(*)$ on a blunt spine. C. A growth cone or axon (arrow) travels along the soma but never makes contact. Note that the neuropil in $\mathbf{B}$ and $\mathbf{C}$ consists of fine unmyelinated axons at this age.

\section{Ultrastructure of the octopus cell region}

At the ultrastractural level, tissue sections from animals at each age were studied without reaction for AChE to evaluate normal morphology. In those tissue sections, as well as those that were reacted for AChE, the tissue morphology was excellent and boutons and synapses were readily visualized. At the youngest age studied (P3) there were few synapses observed and those identified were on blunt somatic spines (Fig. 4A,B). Somatic spines were identified by the protrusion from the perikarya associated with filamentous or flocculent material, as described by Schwartz and Kane (1977). Although axons were observed in juxtaposition to neurons, no evidence of synapses was observed (Fig. 4C). By P5, synapses were more readily visualized, somatic spines were larger, and synapses were identified on both the somatic spines and somata (see Fig. 5A,C,E). By P8, axosomatic synapses were frequent (Fig. 5). We made no attempt to quantify the number of synapses.

\section{Acetylcholinesterase EM histochemistry}

The specific location of the AChE reaction product was determined by overlaying semithin sections onto digitized images of the $50-\mu \mathrm{m}$ sections reacted for AChE (Fig. 6A). The tissue was cut at a slight angle so that the reaction product was always at the leading edge (see Fig. 6B). Using this method, we were able to section stepwise through the PVCN, and by using landmarks (i.e., blood vessels, neuron morphology) we were able to identify specific neurons and their location. Reaction product was localized along axons surrounding cells in the PVCN (see Fig. 5F).

We looked for the localization of reaction product, specifically in boutons, throughout the section including the PVCN and non-PVCN areas. The extensive search through three selected $50-\mu \mathrm{m}$ sections from two animals at each age resulted in the determination that there was an absence of AChE reaction product associated with presynaptic terminals or synaptic junctions (Fig. 5B-F). 

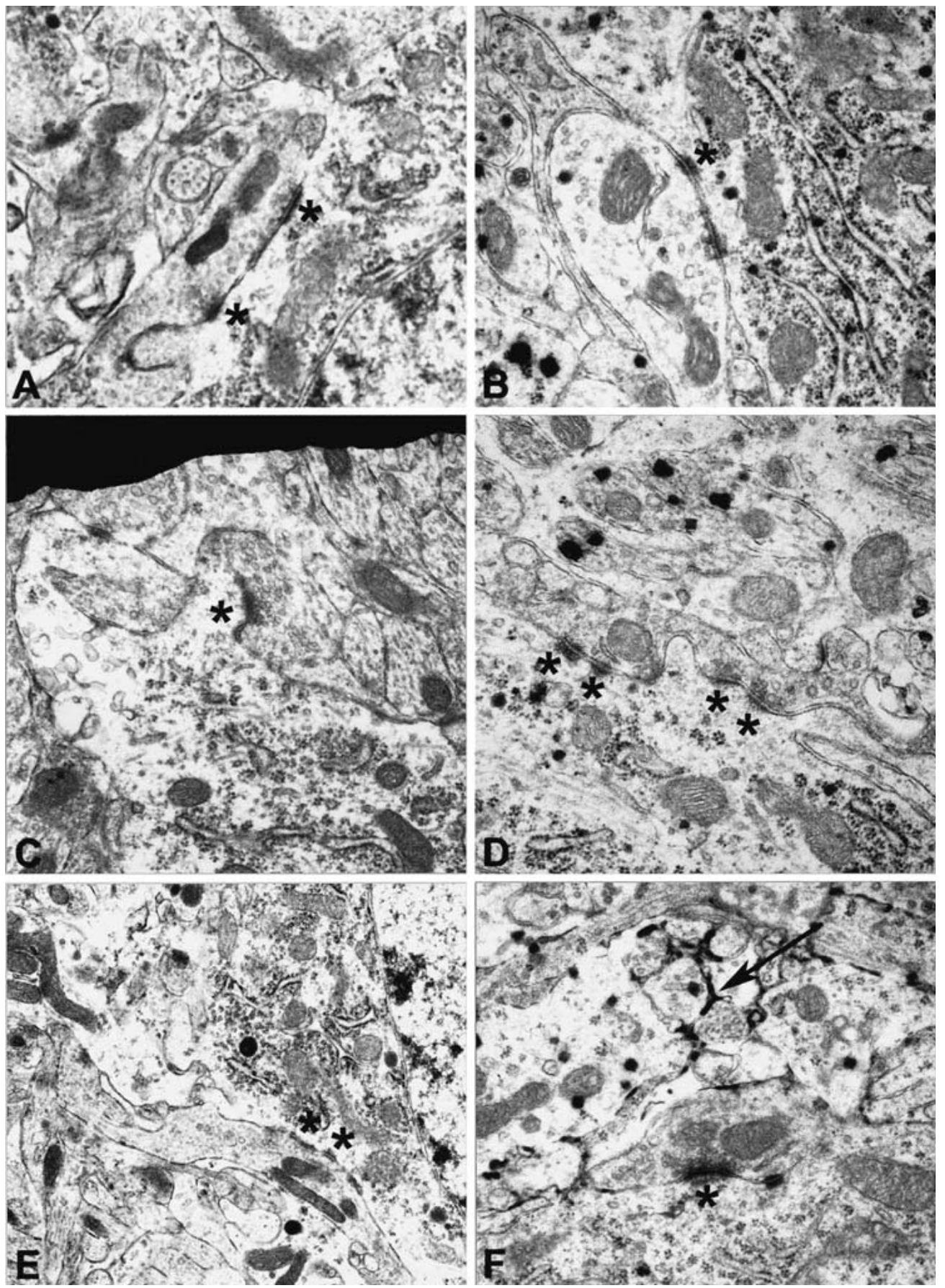

FIG. 5. Several examples of synapses in preparations of the octopus cell region from P5 and P8 animals. The micrographs in the left column $(\mathbf{A}, \mathbf{C}, \mathbf{E})$ are normal histology. The micrographs in the right column (B,D,F) are AChE-positive. Most synapses are axosomatic by these ages $(\mathbf{A}, \mathbf{B}, \mathbf{D}, \mathbf{E}, \mathbf{F})$. Typically, multiple contacts are made by the same axon. Synapses on blunt spines are also present $(\mathbf{C})$. The AChE reaction product was never visualized in any bouton (see B,D). Reaction product was typically associated with axons. The arrow in $\mathbf{F}$ pomts to the typical localization of AChE on axonal membranes. A small amount of AChE reaction product was also observed in the cytoplasm of the cells (see B,D), although in greatly reduced amounts compared to the labeling of axonal membranes.
Vesicular acetylcholine transporter immunocytochemistry

We were unable to obtain labeling of putative cholinergic terminals in the PVCN of rats at any of the developmental ages that we evaluated (P0-10) (see Fig. 7A). In contrast, robustly labeled puncta were observed on the motor nuclei present on the same tissue section (Fig. 7B). 

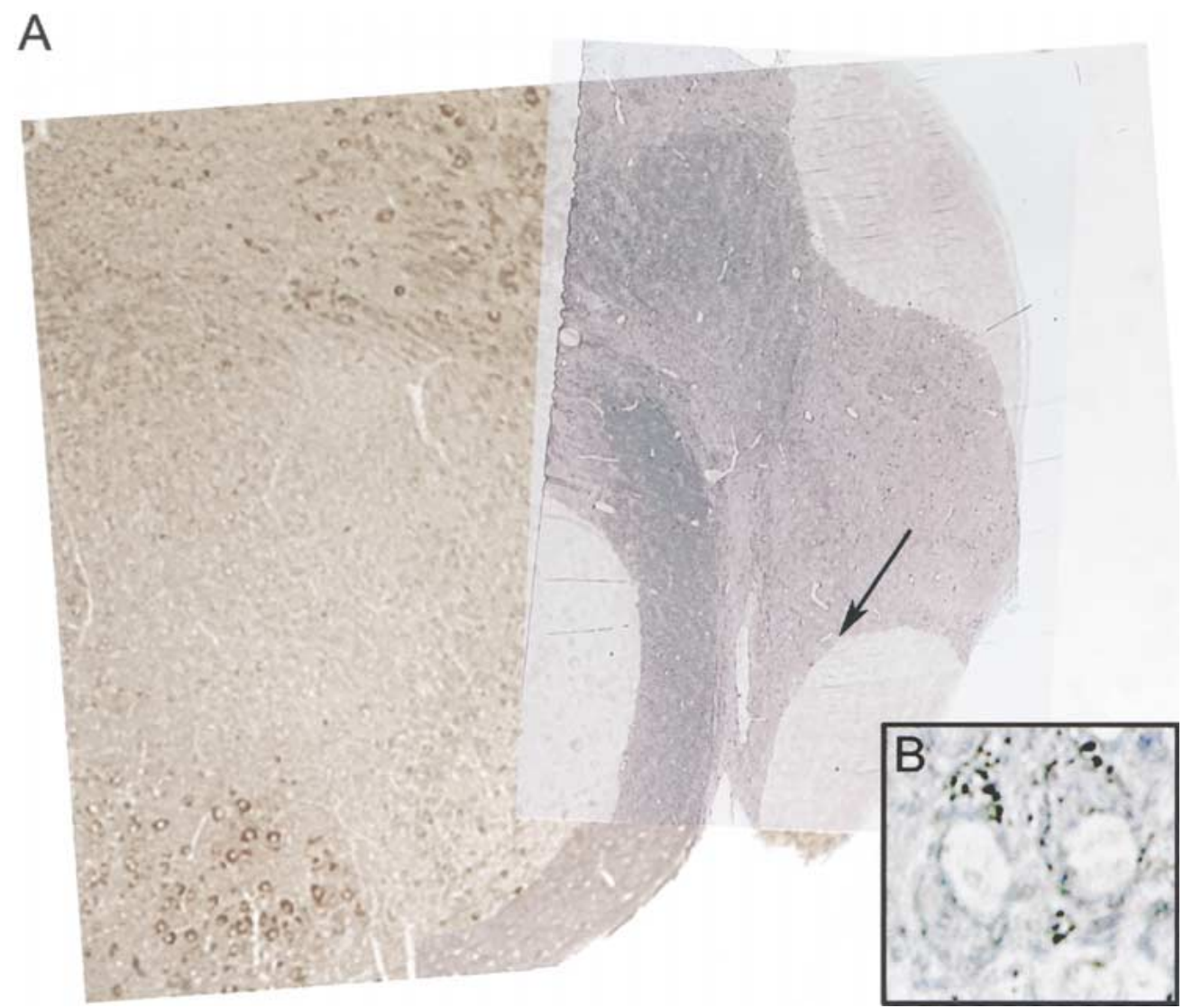

FIG. 6. A. A toluidine blue-stained, light microscopic, semithin section was merged and then overlaid onto a digital image of an AChE-stained vibratome section (the larger underlying section). The block was cut at a slight angle so that the densest $\mathrm{AChE}$ reaction product was always at the leading edge (shown here as the interface

\section{AChE in situ hybridization}

During the course of our research, it was observed that a low level of reaction product was distributed over the perikarya of neurons in the PVCN at the EM level, and was usually associated with ribosomes. We conducted an in situ hybridization study with a cRNA riboprobe to determine if there was AChE being transcribed in the PVCN. The results demonstrated labeling with an antisense but not a sense probe in cells in the PVCN, which was higher in animals at P6 and P10 in comparison with P0 and the P90 (compare the density of labeling in the left panel of Fig. 8). Although the density is greater in the P6 and P10 animals, the labeling in the P90 animal is more heavily clustered over specific cells.

\section{Observations with Dil tracing}

In both the $\mathrm{P} 8$ and $\mathrm{P} 10$ rat pups, labyrinthine efferent axons were extensively labeled with DiI on both sides of the brain. Although nonspecific diffusion of DiI between the edge of the blue semithin) edge and the AChE-positive vibratome section, marked by the arrow). B. A higher magnification of two cells in a semithin section are shown. The technique enabled us to identify the AChE reaction product and its exact location at each step.

obscured the course of the efferent bundle in the region of the dye implant, the intense labeling of this tract became clearly discernable above background where it passes between the descending tract of the trigeminal nerve and the AVCN (Fig. 9A,B). This trajectory of axonal labeling coincides closely with that of the OCB in the adult rat as revealed by tracttracing methods (White and Warr 1983; Osen et al. 1984; Warr and Beck 1996).

An examination of serial sections through the PVCN at a range of magnifications $(6.3-63 \times)$ was made in an attempt to determine whether fluorescently labeled innervation was present $m$ the PVCN or the AVCN of either side. We found that both the PVCN and the AVCN were lacking any significant numbers of terminating axons, although a few scatted fibers and granule cells were present (Fig. 9C,D).

In addition to anterograde labeling of labyrinthine efferent fibers, retrograde labeling was also apparent. Retrogradely labeled OC axons and their respective somata of origin in the SOC were present bilaterally in the P8 pup (Fig. 9E). The most conspicuous 

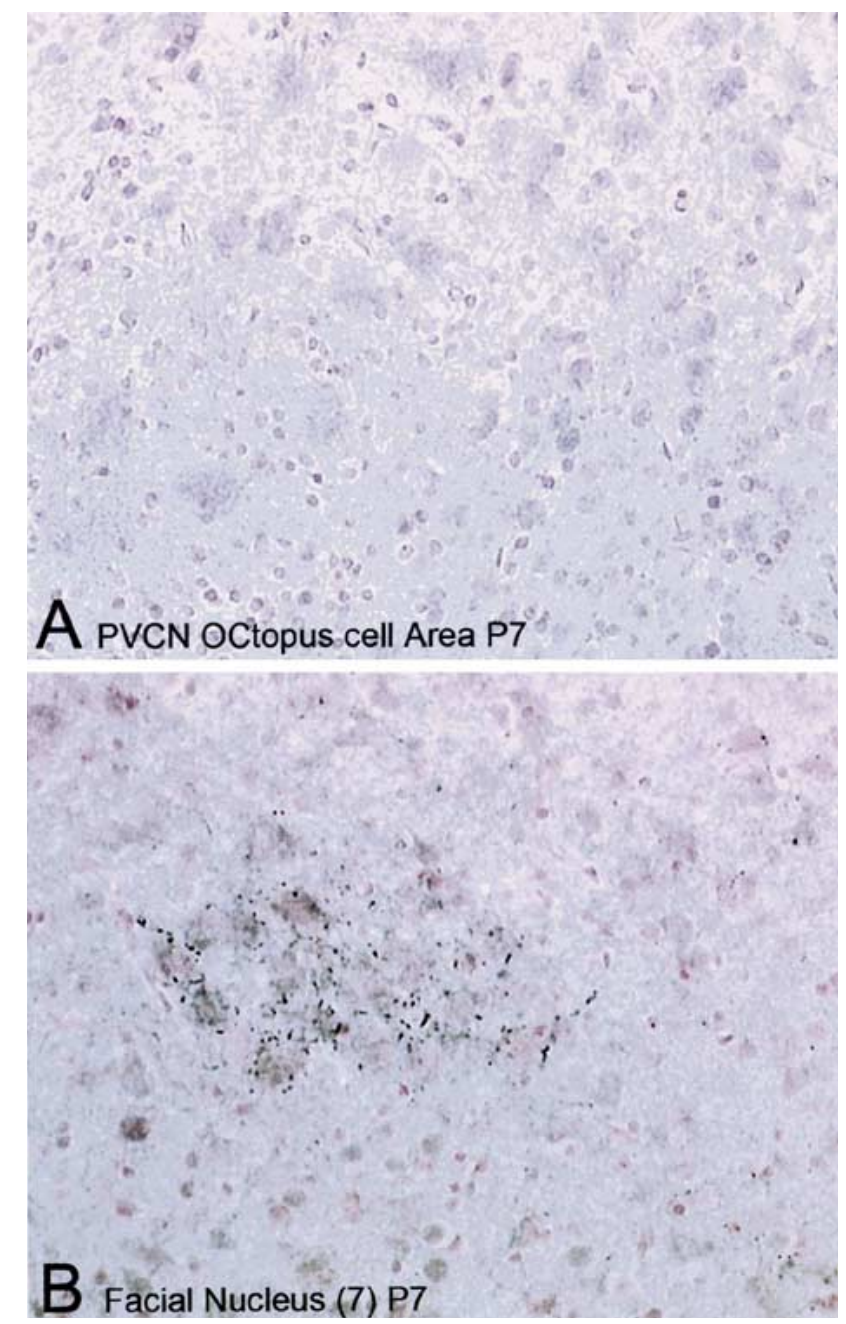

FIG. 7. Immunohistochemistry was conducted using an antibody to the vesicular acetylcholine transport protein (VAChT). A. A representative sample at $\mathrm{P} 7$, when $\mathrm{AChE}$ expression is at peak levels. VAChT was not visualized in the PVCN at any postnatal age investigated (P3-15). B. In the same tissue section, VAChT was readily visualized in many other cell groups, including the facial nucleus shown here.

labeling occurred in the ventral nucleus of the trapezoid body, which contains medial olivocochlear (MOC) neurons in the rat. For reasons that are not clear, labeling of MOC neurons occurred unilaterally in the P10 pup.

\section{DISCUSSION}

On the basis of GAP-43 labeling, Horvath et al. (1997) concluded that synapses in the cochlear nucleus are formed by about P8. The electron microscopic data in the present study support the conclusion that synapses are morphologically mature by P8. Perhaps the most interesting of our observations was the first appearance of synapses on somatic spines by P3 and an increased prevalence by P5-7. Our observations are similar to those of Schwartz and Kane (1977) in the kitten octopus cell region. They described the early appearance of synapses on blunt spines and an increase of identifiable axosomatic synapses during maturation.

Axosomatic synapses in the mature octopus cell region of the rat (Alibardi 2003) have been described. Although axosomatic synapses in the octopus cell region of the adult PVCN may be cholinergic (Vetter et al. 1993; Yao and Godfrey 1999a), ACh is probably mediated primarily by muscarinic receptors (Yao and Godfrey 1995). In our preparations, the expression of $\alpha 7 \mathrm{nAChR}$ transcript and protein are barely above background in the octopus cell region of mature animals (Happe and Morley 1998). Yao and Godfrey (1999b) have reported immunocytochemical labeling of the $\alpha 4 \beta 2$ and $\alpha 7$ receptors in the PVCN, although specific labeling of the octopus cell region was not specifically mentioned and the density of label was not intense.

In this report we identified a transient AChEpositive pathway to the PVCN. The pathway forms a network of axons that envelops neurons in the region of the PVCN that includes the octopus cell region during early postnatal development with peak expression at about P7. AChE is detectable by P3 and continues to be visualized in our preparations in the PVCN until about P12.

Thereafter, the mature distribution of AChE is expressed throughout the CN. Low levels of AChE have been reported in the mature CN (Osen et al. 1984; Godfrey and Matschinsky 1981), but the fiber plexus is clearly absent in the adult. Our results obtained with in situ, hybridization support the histochemical data as demonstrating a bona fide low level of AChE in the CN.

In the present study, AChE EM histochemistry was used to identify putative cholinergic terminals. Our most striking observation was that there was no AChE reaction product associated with boutons or synapses, even though AChE was intensely localized along the axonal membrane. The extensive sampling that we did provides strong evidence that AChE is not present in boutons or associated directly with synapses. Despite the availability of serial sections, we were unable to trace the AChE-positive fibers to their source, but the reaction product was clearly not associated with auditory nerve axons.

To determine if the AChE-positive axons belonged to the olivocochlear system, which is known to be cholinergic, we placed the axonal tracer, DiI, in midline cuts in the floor of the fourth ventricle in young rats (P8-10), but this resulted in no significant number of anterogradely labeled axons or terminal fields in the PVCN, despite clear retrograde labeling 

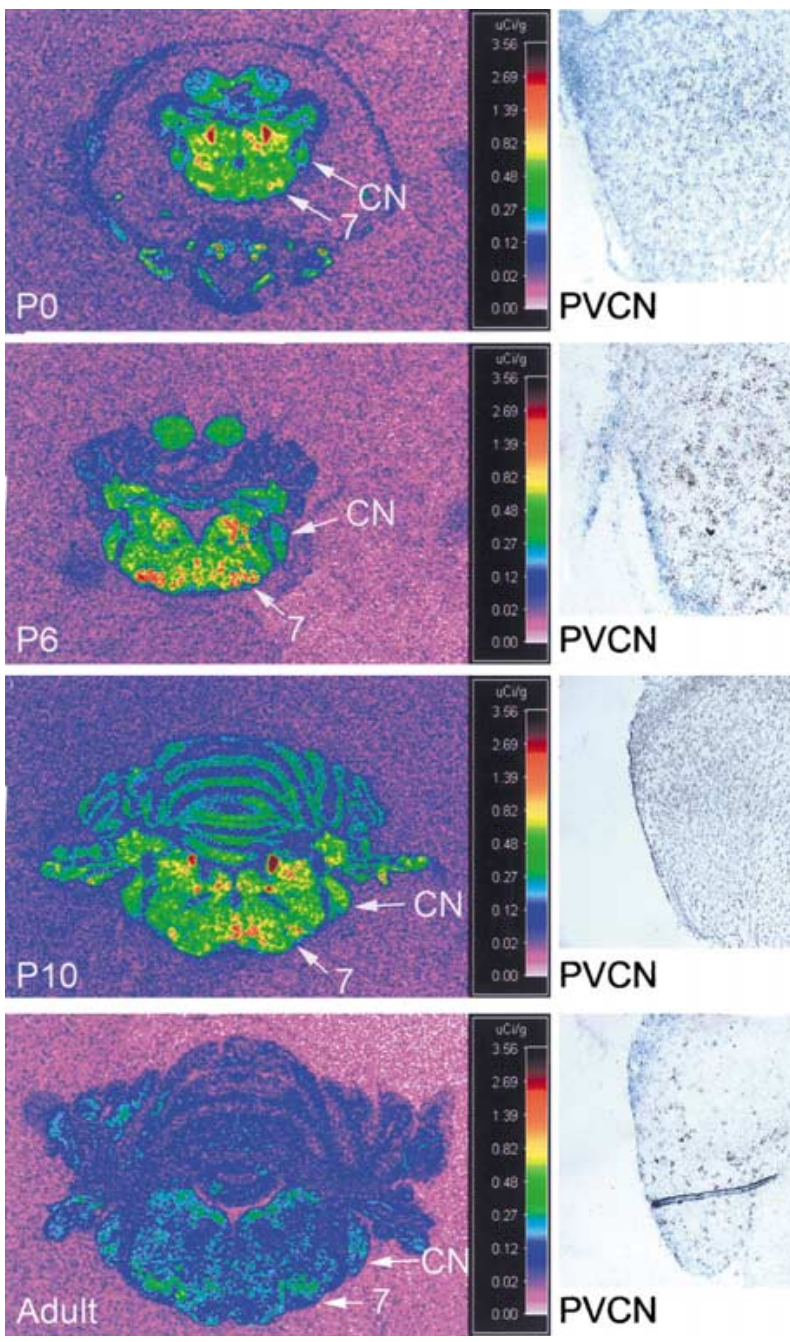

PVCN

of olivocochlear neurons in the superior olivary complex. We interpret this latter finding as indicating that axons belonging to the crossed contingent of the OCB make little if any contribution to the innervation of PVCN at this time period. According to the work of Horvath et al. (2000) in the adult rat, olivocochlear neurons contributing to ventral cochlear nucleus (VCN) on the side opposite their origin include MOC neurons in the VNTB as well as a smaller number of lateral olivocochlear neurons, identified exclusively as shell neurons that surround the lateral superior olivary nucleus (Vetter and Mugnaini 1992). Since it had been previously reported that there are very few projections to the PVCN from the opposite VNTB (Warr and Beck 1996), their apparent absence from the PVCN during postnatal development was not surprising, although we should note that our DiI experiments rule out only the presence of crossed components of the OCB. It remains to be determined whether uncrossed OCB axons might be a source of the transient AChE positive axons in the PVCN of the postnatal rat.
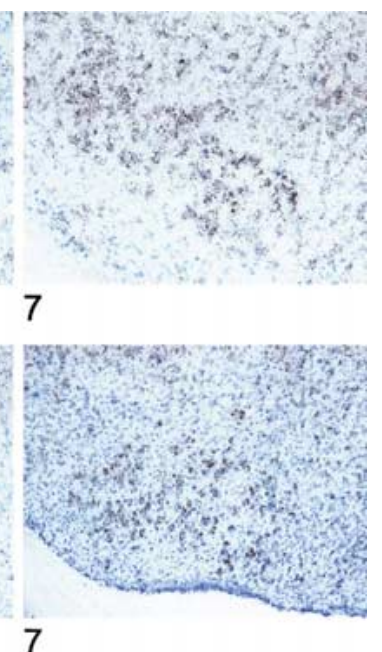

\section{7}

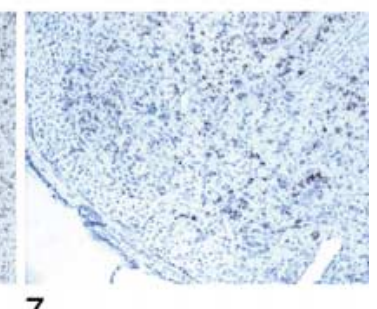

7

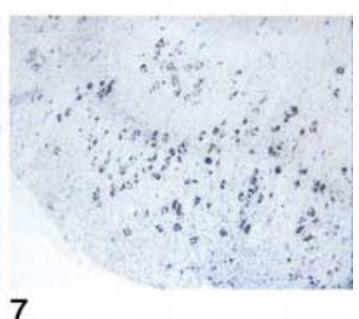

FIG. 8. In situ hybridization with antisense and sense probes specific to the rat $\mathrm{AChE}$ gene. The images on the left were captured from the films using MCID Elite image analysis system. The images in the center and right columns are higher magnifications of the same tissue sections after emulsion-dipping.

Although AChE is not conclusive of a bona fide cholinergic pathway, the coincident upregulation of $\alpha 7$ nAChR mRNA and $\alpha$-bungarotoxin binding (a marker for membrane-bound nAChR protein) suggests that the pathway is cholinergic. The absence of immunolabeling by antibodies to the VAChT protein was surprising and is unlikely to be due to a technical problem. Punctate labeling of terminals in other regions on the same section was robust. Antibodies to VAChT are reported to label terminals in the major cholinergic tracts in rat brain (Arvidsson et al. 1997; Schafer et al. 1998), where they target small, clear synaptic vesicles (Weihe et al. 1996). It is not known if there are cholinergic terminals that are not labeled by VAChT antibodies. Alternatively, $\alpha 7$ nAChRs may be activated by lateral diffusion from ACh release at a nearby location, as is suggested for the $\alpha 7 \mathrm{nAChRs}$ on somatic spines in the ciliary ganglion (Shoop et al. 2002). The absence of VAChT staining could indicate nonvesicular release.

Although AChE may be a factor in guiding neurons in some brain regions or in cell culture systems, 

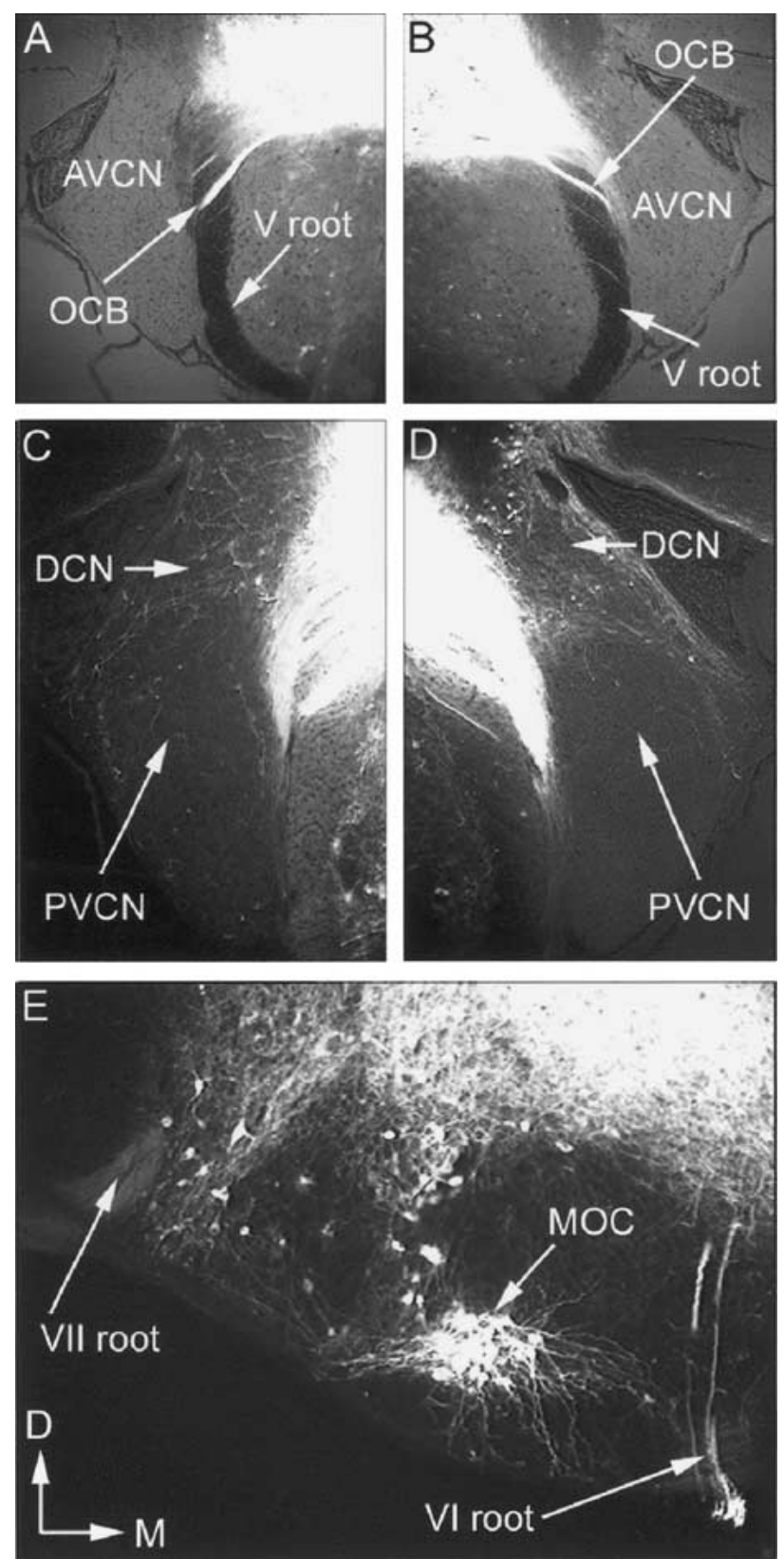

FIG. 9. Images of Dil labeling at P8 following dye implantation of the severed OCB at the midline. A,B. The labeled OCB is shown at the level of the anteroventral cochlear nucleus (AVCN) passing dorsal to the descending tract of the trigeminal nerve ( $\mathrm{V}$ root) on the left and right sides. C,D. Images of the DCN and PVCN of each side showing extremely sparse axonal labeling in the PVCN and only a slightly greater amount in the DCN. E. Axonal and somatic labeling in the left superior olivary complex at a level rostral to the lateral superior olivary nucleus showing a dense cluster of medial olivocochlear (MOC) neurons in the left ventral nucleus of the trapezoid body. Generally weak axonal labeling is present in the facial (VII) and abducens $(\mathrm{VI})$ roots.

it is unlikely to have this role in the octopus cell region. The presence of AChE is postnatal and peak expression is at $\mathrm{P} 7-10$, when the axons are already in place. Instead, the expression of AChE is temporally correlated with the maturation of synapses. Both AChE and the ACh (through $\alpha 7 \mathrm{nAChR}$ ) may have a role in inducing gene expression of primary neurotransmitter receptors and/or stabilizing connections. There is an emerging literature that supports the role of AChE and ACh in postnatal developmental events. For example, there is evidence that AChE upregulates AMPA receptors in CNS areas undergoing synaptogenesis but does not affect NMDA receptors (Olivera et al. 2003). Conversely, NMDA postsynaptic electrophysiological activity and postsynaptic gene expression are regulated through $\alpha 7 \mathrm{nAChRs}$ (Aramakis and Metherate 1998; Aramakis et al. 2000; Hsieh et al. 2002). A similar role for ACh and AChE in the induction of appropriate subunit gene expression in the PVCN is likely.

Prior to the maturation of glutamatergic synapses, neural activity must be generated from another source. A certain level of functioning (neural activity) is necessary for synapses to achieve stability (Shatz 1996). Neurons with somatic spines are characterized by clusters of postsynaptic $\alpha 7$ nAChRs in the early development of the chick ciliary ganglion (Shoop et al. 1999). ACh, through $\alpha 7$ nAChRs, stabilizes electrophysiological activity at those synapses (Chang and Berg 1999).

Our morphological data are consistent with the conclusions of Brugge and O'Connor (1984) that the emergence of electrophysiological activity in the PVCN does not depend on afferent activity generated in the cochlea and auditory nerve by the acoustic environment. The source of this excitatory activity in octopus cells is not known. However, the only evidence of a nonglutamatergic excitatory pathway into the octopus cell region is the putative cholinergic pathway that we identify in this report and in previous studies of the early postnatal expression of $\alpha 7 \mathrm{nAChR}$ in this region (Morley and Happe 2000). In the visual system, large propagating waves driven by ACh and mediated by nicotinic receptors are recorded in the retina before eye opening (Bansal et al. 2000). By analogy, we suggest that neurons in the octopus cell area and surrounding PVCN are driven by ACh before the onset of hearing. The presence of AChE-positive axons may indicate the cholinergic nature of the input and/or AChE may have a noncatalytic function, but the coincident appearance of AChE and $\alpha 7$ nAChRs suggests that they are both important to the proper maturation of the octopus cell region.

\section{ACKNOWLEDGMENTS}

This research was supported by NIH Grant DC000215 to BJM and WBW. The authors thank Rick Vaughn, Tom Barger, Jo Ellen Beck Boche, and Theresa Holderread for 
their excellent technical assistance. The authors greatly appreciate the assistance of Dr. Kent Morest in identifying somatic spines and synapses in the electron micrographs.

\section{REFERENCES}

AlibARDI L. Ultrastructure and immunocytochemical characteristics of cells in the octopus cell area of the rat cochlear nucleus, comparison with multipolar cells. Ann. Anat. 185:21-33, 2003.

Aramakis VB, Metherate R. Nicotine selectively enhances NMDA receptor-mediated synaptic transmission during postnatal development in sensory neocortex. J. Neurosci. 18:8485-8495, 1998.

Aramakis VB, Hsieh CY, Leslie FM, Metherate R. A critical period for nicotine-induced disruption of synaptic development in rat auditory cortex. J. Neurosci. 20:6106-6116, 2000.

Arvidsson U, Riedi M, Elde R, Meister B. Vesicular acetylcholine transporter (VAChT) protein: a novel and unique marker for cholinergic neurons in the central and peripheral nervous systems. J. Comp. Neurol. 378:454-467, 1997.

Bansal A, Singer JH, Hwang BJ, Xu W, Beaudet A, Feller MB. Mice lacking specific nicotinic acetylcholine receptor subunits exhibit dramatically altered spontaneous activity patterns and reveal a limited role for retinal waves in forming $\mathrm{ON}$ and $\mathrm{OFF}$ circuits in the inner retina. J. Neurosci. 20:7672-7681, 2001.

Bennett-Clarke CA, Chiaia NL, Rhoades RW. Differential expression of acetylcholinesterase in the brainstem, ventrobasal thalamus and primary somatosensory cortex of perinatal rats, mice and hamsters. Somatosens. Motor Res. 16:269-279, 1999.

Bigbee JW, Sharna KV, Chan EL-P, Bogler O. Evidence for the direct role of acetylcholinesterase in neurite outgrowth in primary dorsal root ganglion neurons. Brain Res. 861:354-362, 2000.

Bina KG, Guzman P, Broide RS, Leslie FM, Smith MA, O'Dowd DK. Localization of alpha 7 nicotinic receptor subunit mRNA and alpha-bungarotoxin binding sites in developing mouse somatosensory thalamocortical system. J. Comp. Neurol. 363:321-332, 1995.

Brimijoin S, Hammond P. Transient expression of acetylcholinesterase messenger RNA and enzyme activity in developing rat thalamus studied by quantitative histochemistry and in situ hybridization. Neuroscience 71:555-565, 1996.

Broide RS, O'Connor LT, Smith MA, Smith JA, Leslie FM. Developmental expression of alpha7 neuronal nicotinic receptor messenger RNA in the rat sensory cortex and thalamus. Neuroscience 67:83-94, 1995.

Bruce LL, Christensen MA, Warr WB. Postnatal development of efferent synapses in the rat cochlea. J. Comp. Neurol. 423:532-548, 2000.

Brugge JF, O'Connor TA. Postnatal functional development of the dorsal and posteroventral cochlear nuclei of the cat. J. Acoust. Soc. Am. 75:1548-1562, 1984.

Chang KT, Berg DK. Nicotinic acetylcholine receptors containing $\alpha 7$ subunits are required for reliable synaptic transmission in situ. J. Neurosci. 19:3701-3710, 1999.

Coleman BA, TAYlor P. Regulation of acetylcholinesterase expression during neuronal differentiation. J. Biol. Chem. 8:4410-4416, 1996.

ECKenstein F, SOFRONIEw MV. Identification of central cholinergic neurons containing both choline acetyltransferase and acetylcholinesterase and of central neurons containing only acetylcholinesterase. J. Neurosci. 3:2286-2291, 1983.

FucHS JL. $\left[{ }^{125} \mathrm{I}\right]$ alpha-bungarotoxin binding marks primary sensory area developing rat neocortex. Brain Res. 501:223-234, 1989.

Geula C, Mesulam MM, Tokuno H, Kuo CC. Developmentally transient expression of acetylcholinesterase within cortical pyramidal neurons of the rat brain. Dev. Brain Res. 76:23-31, 1993.

Godfrey DA, Matschinsky FM. Quantitative distribution of choline acetyltransferase and acetylcholinesterase activities in the rat cochlear nucleus. J. Histochem. Cytochem. 29:720-730, 1981.

HAPpe HK, MoRley BJ. Nicotinic acetylcholine receptors in rat cochlear nucleus, $\left[{ }^{125} \mathrm{I}\right]$ - $\alpha$-bungarotoxin receptor autoradiography and in situ hybridization of $\alpha 7$ nAChR subunit mRNA. J. Comp. Neurol. 397:163-180, 1998.

Harrison JM, Irving R. The organization of the posterior ventral cochlear nucleus in the rat. J. Comp. Neurol. 126:391-401, 1966.

Henderson JR. The use of silver for intensifying sulfide deposits in the cholinesterase technique. Stain Tech. 12:101.

Horvath M, Forster CR, Illing R-B. Postnatal development of GAP43 immunoreactivity in the auditory brainstem of the rat. J. Comp. Neurol. 382:104-115, 1997.

Horvath M, Kraus KS, Illing R-B. Olivocochlear neurons sending axon collaterals into the ventral cochlear nucleus of the rat. J. Comp. Neurol. 422:95-105, 2000.

Hsieh CY, Leslie FM, Metherate R. Nicotine exposure during a postnatal critical period alters NR2A and NR2B mRNA expression in rat auditory forebrain. Brain Res. Dev. Brain Res. 133:19-25, 2002.

KaRnOvsKY MJ, Roots L. A “direct coloring”" thiocholine method for cholinesterase. J. Histochem. Cytochem. 12:219-221, 1964.

Koelle GB, Friedenwald JS. A histochemical method for localizing cholinesterase activity. 70:617-622, 1949.

Koenigjsberger C, Chiappa S, Brimijoin S. Neurite differentiation is modulated in neuroblastoma cells engineered for altered levels of acetylcholinesterase expression. J. Neurochem. 69:1389-1397, 1997.

KRISTT DA. Acetylcholinesterase in the ventrobasal thalamus, transience and patterning during ontogenesis. Neuoscience 10:923-939, 1983

KRISTT DA, WALDMAN JV. The origin of the acetylcholinesterase-rich afferents to layer IV of infant somatosensory cortex, a histochemical analysis following lesions. Anat. Embryol. 163:31-41, 1981.

Levy RB, AOKI C. $\alpha 7$ nicotinic acetylcholine receptors occur at postsynaptic densities of AMPA receptor-positive and -negative excitatory synapses in rat sensory cortex. J. Neurosci. 22:5001-5015, 2002.

Morley BJ. The embryonic and postnatal expression of the nicotinic receptor alpha 3 subunit in rat lower brainstem. Mol. Brain Res. 48:407-412, 1997.

Morley BJ, Happe HK. Cholinergic receptors: Dual roles in transduction and plasticity. Hear Res. 147:104-112, 2000.

Olivera S, Henley JM, Rodriguez-Ithurralde D. AMPA receptor potentiation by acetylcholinesterase is age-dependently upregulated at synaptogenesis sites of the rat brain. Int. J. Devel. Neurosci. 21:49-61, 2003.

Osen KK, Mugnaini E, Dahl AL, Christiansen AH. Histochemical localization of acetylcholinesterase in the cochlear and superior olivary nuclei. A reappraisal with emphases on the cochlear granule cell system. Arch. Ital. Biol. 122:169-212, 1984.

Robertson RT, Mostamand F, Kageyama GH, Gallardo KA, Yu J. Primary auditory cortex in the rat: transient expression of acetylcholinesterase activity in developing geniculocortical projections. Dev. Brain Res. 15:81-95, 1991

SCHAFER K-H, EIdEN LE, WeiHe E. Cholinergic neurons, terminal fields revealed by immunohistochemistry for the vesicular acetylcholine transporter. I: Central nervous system. Neuroscience 84:331-359, 1998.

Schwartz AM, Kane ES. Development of the octopus cell area in the cat ventral cochlear nucleus. Am. J. Anat. 148:1-18, 1977. 
Shatz CJ. Emergence of order in visual system development. Proc. Natl. Acad. Sci. USA 93:602-608, 1996.

Shoop RD, Martone ME, Yamada N, Ellisman MH, Berg DK. Neuronal acetylcholine receptors with alpha7 subunits are concentrated on somatic spines for synaptic signaling in embryonic chick ciliary ganglia. J. Neurosci. 19:692-704, 1999.

Shoop RD, Esquenazi E, Yamada N, Ellisman MH, Berg DK. Ultrastructure of a somatic spine mat for nicotinic signaling in neurons. J. Neurosci. 22:748-756, 2002.

Vetter DE, Cozzari C, Hartman BK, Mugnaini E. Choline acetyltransferase in the rat cochlear nuclei, immunolocalization with a monoclonal antibody. In: Merchan MA, Juiz JM, Godfrey DA, Mugnaini E (eds) The Mammalian Cochlear Nuclei, Organization and Function. Plenum, New York, pp 279-290, 1993.

Vetter DE, Mugnaini E. Distribution and dendritic features of three groups of rat olivocochlear neurons. Anat. Embryol. 185:1-16, 1992.
WARR WB, BECK JE. Multiple projections from the ventral nucleus of the trapezoid body in the rat. Hear Res. 93:83-101, 1996.

Weine E, Tao-Cheng JH, Schafer MK, Erickson JD, Eiden LE. Visualization of the vesicular acetylcholine transporter in cholinergic nerve terminals and its targeting to a specific population of small synaptic vesicles. Proc. Natl. Acad. Sci. 93:3547-3552, 1996.

WHITE JS, WARR WB. The dual origins of the olivocochlear bundle in the albino rat. J. Comp. Neurol. 219:203-214, 1983.

YAO W, GODFREY DA. Immunohistochemistry of muscarinic acetylcholine receptors in rat cochlear nucleus. Hear Res. 89:76-85, 1995.

Yao W, Godfrey DA. Vesicular acetylcholine transporter in the rat cochlear nucleus, an immunohistochemical study. J. Histochem. Cytochem. 47:83-90, 1999a.

YAo W, Godfrey DA. Immunolocalization of alpha4 and alpha7 subunits of nicotinic receptors in rat cochlear nucleus. Hear Res. 128:97-102, 1999b. 